\title{
Inhibition of Protein Kinase C Prevents Purkinje Cell Death But Does Not Affect Axonal Regeneration
}

\author{
Abdel M. Ghoumari, ${ }^{1}$ Rosine Wehrlé, ${ }^{1}$ Chris I. De Zeeuw, ${ }^{2}$ Constantino Sotelo, ${ }^{1}$ and Isabelle Dusart ${ }^{1}$ \\ 1/nstitut National de la Santé et de la Recherche Médicale Unité 106, Hôpital de la Salpêtrière, 75651 Paris Cedex 13, \\ France, and 2Department of Anatomy, Neuroscience Institute, Faculteit der Geneeskunde en \\ Gezondheidswetenschappen, Erasmus, University Rotterdam, 3000 DR Rotterdam, The Netherlands
}

In organotypic cultures, mouse Purkinje cells regenerate their axons from embryonic day 18 (E18) to postnatal day 0 (P0), die of apoptosis between P1 and P7, and survive but do not regenerate at $\mathrm{P} 10$. This particular behavior of Purkinje cells did not allow us to find out when the developmental switch between regeneration and lack of regeneration occurs. This work was undertaken to suppress Purkinje cell apoptosis and to investigate whether the same molecules that prevent apoptosis could also influence axonal growth, regeneration, or both. We show that brain-derived neurotrophic factor, neurotrophin 3 , and insulin-like growth factor I have marginal effects on P3 Purkinje cell death. The use of Gö6976 [a protein kinase C (PKC) inhibitor] or a transgenic mouse line, in which a pseudosubstrate PKC inhibitor has been specifically targeted to Purkinje cells, prevents the massive Purkinje cell death in P3 organotypic cultures. In addition, Gö6976 promotes axotomized Purkinje cell survival up to P7. Thus, the inhibition of PKC activity is able to prevent Purkinje cell apoptosis in organotypic cultures. Furthermore, Gö6976 increases the outgrowth of dendrites and axon collateralization, as shown after gene gun enhanced green fluorescent protein transfection. In contrast, PKC inhibitors do not influence the axonal regenerative capability of Purkinje cell during development; the latter decreases between E18 and P7 after the same time course in control and Gö6976-treated slices. Thus, because inhibition of PKC prevents Purkinje cell death but does not affect axonal regeneration, these two events (cell death and axonal regeneration) seem to be differentially regulated.

Key words: axotomy; apoptosis; trophic factor; cerebellum; PKC inhibitor; development
Purkinje cells offer a good system for studying the intracellular pathways leading to neuronal death and regeneration during development, because their survival and regenerative capabilities are very clearly age-related (Dusart et al., 1997; Gianola and Rossi, 2001). In organotypic cultures, these neurons die of apoptosis when the explants are taken from postnatal day 1 (P1) to P7 mouse pups, and they are able to regenerate their axons before P1 and not after P7 (Dusart et al., 1997; Ghoumari et al., 2000).

There is a positive correlation between the capacity of a neuron for axon regeneration and its probability of dying after axotomy, suggesting that identical molecular pathways can lead to either regeneration or cell death (for review, see Herdegen et al., 1997; Goldberg and Barres, 2000). Indeed, the postaxotomy expression of molecules such as c-Jun and growth-associated protein 43 (GAP-43) have been correlated with both cell death and axonal regeneration (Herdegen et al., 1997; Gagliardini et al., 2000; Wehrlé et al., 2001). In addition, the survival of neurons depends on trophic factors, particularly neurotrophins, which can

Received Dec. 14, 2001; revised Dec. 14, 2001; accepted Jan. 28, 2001.

This work was supported by Institut National de la Santé et de la Recherche Médicale Grant U106, the European Community, and Biotechnology Program Grant BIO4 CT98 0293. C.S. and I.D. are Centre National de la Recherche Scientifique investigators. C.I.D.Z. is supported by the Human Frontier Scientific Program, Dutch Organization for Fundamental Research-Life Sciences Committee, and Dutch Organization for Fundamental Research-Medical CommitteePIONIER. We thank Dr. D. Linden for help with the electrophysiological assay to measure PKC activity; Drs. M. S. Airaksinen and M. Meyer for the gift of CaBP knock-out mice; Drs. P. Gaspar, S. Marty, and J. P. Rio for critical reading of this manuscript; and D. Le Cren for photographic assistance.

Correspondence should be addressed to Isabelle Dusart, Institut National de la Santé et de la Recherche Médicale Unité 106, Hôpital de la Salpêtrière, 75651 Paris Cedex 13, France. E-mail: dusart@infobiogen.fr.

Copyright () 2002 Society for Neuroscience $0270-6474 / 02 / 223531-12 \$ 15.00 / 0$ act either alone or in combination (Henderson, 1996), and these factors also promote neuritic growth (Levi-Montalcini, 1987; Campenot, 1994; Meyer-Franke et al., 1995). Thus, factors preventing neuronal death could also in theory influence axonal regeneration. In the present study, some of the factors that regulate Purkinje cell survival in organotypic cultures have been identified, and tested for promotion of axonal growth, axonal regeneration, or both after axotomy.

We found that neurotrophins are not sufficient to overcome the apoptotic Purkinje cell death occurring in organotypic cultures of P3 mice cerebella. Because of the important part taken by protein kinases in cellular responses to growth factors and other signaling molecules (Nishizuka, 1992), we have tested a number of protein kinase (PK) inhibitors. Here, we report data showing that Gö6976, a potent PKC inhibitor, prevents the Purkinje cell death in P3 organotypic cultures. The effects of PKC inhibitors really result from the direct inhibition of Purkinje cell enzymatic activities, because these neurons survive in P3 cerebellar explants taken from a transgenic mouse line, in which a pseudosubstrate PKC inhibitor was specifically expressed in Purkinje cells under the control of the pcp-2(L7) gene promoter (De Zeeuw et al., 1998). Moreover, the preventive action of Gö6976 spans the entire period of in vitro Purkinje cell death, because from embryonic day 18 (E18) to P7, the number of surviving Purkinje cells is much higher in Gö6976-treated cultures than in untreated ones. Gö6976 treatment also increases axon collateralization of Purkinje cells up to P7. On the contrary, even in the presence of Gö6976, regeneration of Purkinje cell axons decreases rapidly up to P7. Thus, inhibition of PKC prevents Purkinje cell death without affecting axon regeneration and, because the program 
involving PKC during Purkinje cell death after axotomy ends after P7, whereas the one involving axonal regeneration ends between P3 and P7, we suggest that survival and axonal regeneration are differentially regulated during development.

\section{MATERIALS AND METHODS}

Slice cultures. E18 fetuses and P0, P1, P3, P5, P7, and P10 Swiss mice (Janvier, Le Genest St Isle, France) were used. E0 was the mating day, and $\mathrm{P} 0$ was the day of birth. Fetuses were obtained by cesarean delivery from pregnant mice anesthetized with chloral hydrate $(350 \mathrm{mg} / \mathrm{kg}$, i.p.). For each experiment, at least three animals and 18 slices were used. After decapitation, brains were dissected out into cold Gey's balanced salt solution containing $5 \mathrm{mg} / \mathrm{ml}$ glucose, and meninges were removed. Cerebellar parasagittal slices ( 350 or $250 \mu \mathrm{m}$ thick) were cut on a McIlwain tissue chopper and transferred onto membranes of $30 \mathrm{~mm}$ Millipore culture inserts with $0.4 \mu \mathrm{m}$ pore size (Millicell; Millipore, Bedford, MA). Slices were maintained in culture in six-well plates containing $1 \mathrm{ml}$ or in $10 \mathrm{~cm}$ culture dishes containing $3 \mathrm{ml}$ of medium at $35^{\circ} \mathrm{C}$ in an atmosphere of humidified $5 \% \mathrm{CO}_{2}$. The medium was composed of $50 \%$ basal medium with Earle's salts (Invitrogen, Gaithersburg, MD), 25\% HBSS (Invitrogen), $25 \%$ horse serum (Invitrogen), L-glutamine $(1 \mathrm{~mm})$, and $5 \mathrm{mg} / \mathrm{ml}$ glucose (Stoppini et al., 1991).

Some cultures were transected with a glass knife through lobules III and VIII under a dissecting microscope. The two parts were gently separated to ensure a complete axotomy. The dorsal parts were apposed with halves of P10 calbindin-knockout $(\mathrm{CaBP}-/-)$ cerebellar slices (Airaksinen et al., 1997), which allowed us a more precise analysis of the fate of the regenerating axons of Swiss Purkinje cells immunostained with CaBP (Dusart et al., 1997).

Treatments with trophic factors, protein kinase inhibitors, and the L7PKCI transgenic mouse line. Brain-derived neurotrophic factor (BDNF), neurotrophin 3 (NT-3), insulin-like growth factor I (IGF-I), and PK inhibitors were applied, aimed at increasing Purkinje cell survival in P3 organotypic cultures. An anti-human BDNF (Promega) and dinitroquinoxaline-2,3-dione (DNQX; Research Biochemicals, Bioblock Scientific) were applied to block BDNF-TrkB interactions and nonNMDA glutamate receptors, respectively. BDNF, NT-3, and IGF-I were purchased from Chemicon (Temecula, CA), and PK inhibitors were from Calbiochem (France Biochem, Meudon, France). Dose responses were determined by treating wild-type cerebellar slices with different concentrations of each compound, and we retained only the doses with maximal efficiency. The latter were BDNF (100 ng/ $/$ l per slice), NT-3 (100 ng $/ \mu \mathrm{l}$ per slice), IGF-I (100 ng/ $\mu \mathrm{l}$ per slice), anti-BDNF (100 $\mu \mathrm{g} / \mathrm{ml})$, DNQX (100 $\mu \mathrm{M}$; Marty et al., 1996; Seil and Drake-Baumann, 2000), KT5720 (PKA inhibitor, $9 \mu \mathrm{M}$ ), KT5823 (PKG inhibitor, $20 \mu \mathrm{M}$ ), and Gö6976 (PKC inhibitor, $2 \mu \mathrm{M}$ ). The appropriate dilutions of neurotrophins and IGF-I were added directly on the slices (1 $\mu \mathrm{l} /$ slice), whereas those corresponding to anti-BDNF, DNQX, and PK inhibitors were added to culture medium. The cerebellar slices were maintained in culture for $5 \mathrm{~d}$ in vitro (DIV). The medium, added with the respective drugs, was replaced once after $2 \mathrm{~d}$. The nontreated slices or slices treated with DMSO were considered controls.

In addition, to test the role of the specific inhibition of PKC in Purkinje cells, we used P3 cerebella $(n=17)$ taken from L7-PKCI transgenic mice. In these mice, the pseudosubstrate PKC inhibitor PKC[19-31] was selectively expressed in Purkinje cells under the control of the pcp-2(L7) gene promoter (De Zeeuw et al., 1998). The heterozygous mice were mated, and the transgenic were determined by PCR.

Antibodies and staining procedures. Rabbit polyclonal antibody against CaBP (diluted 1:5000; Swant, Bellinzona, Switzerland) was used to visualize Purkinje cells. A mouse monoclonal antibody against parvalbumin (diluted 1:10,000; Sigma, Saint Louis, MO) was used to visualize Purkinje cells and interneurons of the molecular layer in CaBP-knockout mice (Celio, 1990).

The cultures and cocultures were fixed in $4 \%$ paraformaldehyde in phosphate buffer $(0.1 \mathrm{M}) \mathrm{pH} 7.4$, for $1 \mathrm{hr}$ at room temperature. After washing in PBS, the slices were taken off the Millicell and processed for immunocytochemistry. In all cases, the slices were incubated for $1 \mathrm{hr}$ in $0.12 \mathrm{M}, \mathrm{pH} 7.4$, phosphate buffer containing $0.9 \% \mathrm{NaCl}, 0.25 \%$ Triton-X, $0.2 \%$ gelatin, $0.1 \%$ sodium azide (PBSGTA) and $0.1 \mathrm{~m}$ lysine before applying the first antibodies, diluted in PBSGTA overnight. The first antibodies were revealed with the following secondary antibodies: goat anti-mouse Cy3 (1:200 dilution; Jackson ImmunoResearch, West Grove, PA), goat anti-rabbit Cy3 (1:200 dilution; Jackson ImmunoResearch), and sheep anti-rabbit FITC (1:200 dilution; Silenus Laboratories, Hawthorne, Australia). After $2 \mathrm{hr}$ of incubation in buffer containing the secondary antibodies, the slices were washed several times in $0.12 \mathrm{M}$ phosphate buffer, mounted in mowiol (Calbiochem, Bad Soden, Germany), and analyzed using a Leica (Nussloch, Germany) DMR microscope.

Developmental expression of PKC in the cerebellum. To check for the presence of PKC in Purkinje cells, we used Rim-1, a fluorescent derivative of the bisindolylmaleimide inhibitors of PKC that can be used as a fluorescent probe for PKC (Chen and Poenie, 1993). Mouse pups at P3 and P10, at least three animals for each age, were perfused through the aorta with $0.12 \mathrm{M}$ phosphate-buffered, $\mathrm{pH} 7.4,4 \%$ paraformaldehyde. Brains were dissected out, post-fixed $4 \mathrm{hr}$, and cryoprotected in $30 \%$ sucrose for $2 \mathrm{~d}$. The cerebella were cut in the sagittal plane $(24-\mu \mathrm{m}$-thick free-floating sections) on a freezing microtome. The sections were incubated for $1 \mathrm{hr}$ in $0.12 \mathrm{M}, \mathrm{pH} 7.4$, phosphate buffer containing $0.9 \% \mathrm{NaCl}$, $0.2 \%$ gelatin, $0.1 \%$ sodium azide (PBSGA), and $0.1 \mathrm{~m}$ lysine before applying the $\mathrm{CaBP}$ antibodies (see above), diluted in PBSGA overnight. After several washes, sections were incubated for $2 \mathrm{hr}$ in a mixture of Rim-1 (1:50; Molecular Probes, Eugene, OR) and anti-rabbit FITC (1:200; Silenus Laboratories) to double label Rim-1- and CaBPcontaining cells. Then the slices were washed several times in $0.12 \mathrm{M}$ phosphate buffer, mounted in mowiol (Calbiochem), and analyzed using a Leica DMR microscope. Gray level images were taken using a camera cool scan (Princeton Instrument) and then treated and assembled using Adobe (Mountain View, CA) Photoshop software.

Quantification of Purkinje cell survival. To determine the Purkinje cell survival in the cultures, the neurons were immunostained with an antibody against $\mathrm{CaBP}$ and quantified under a fluorescence microscope (Leica DMR). Three groups of slices have been defined (Dusart et al., 1997; Ghoumari et al., 2000). Briefly, the first group (denoted I) included the slices with few and dispersed Purkinje cells, i.e., those with no compact group of $>20$ Purkinje cells (Fig. $1 A$ ). The second group (II) included the slices containing one or two compact groups of $>20$ Purkinje cells (Fig. $1 B$ ). The third group (III), with a maximum of Purkinje cell survival, included the slices containing more than three compact groups of at least 20 Purkinje cells or one compact group of $>50$ Purkinje cells (Fig. 1C). For each case, the percentages of slices included in groups I-III were calculated.

Because of the large difference in the numbers of Purkinje cells in classes I-III, we have counted the total number of Purkinje cells per slice when the differences between the classes were questionable, i.e., for wild type and transgenics (Fig. 2D). In these cases, the numbers of Purkinje cells per slice were counted, and the means and SEMs were calculated. The statistical significance of the difference between the mean number of Purkinje cells per slice was performed using the parametric Student's $t$ test. All $p$ values given are two-sided, and $p<0.05$ was considered statistically significant.

Inhibition of PKC activity in L7-PKCI Purkinje cells. Embryonic mouse cerebellar cultures (E16) were prepared and maintained according to the method of Schilling et al. (1991). Cultures were maintained in vitro for $8-16 \mathrm{~d}$ at the time of use in electrophysiological experiments (described by De Zeeuw et al., 1998). In short, patch electrodes were attached to Purkinje cell somata. Cells were bathed in a solution that contained (in $\mathrm{mm}$ ): $140 \mathrm{NaCl}, 5 \mathrm{KCl}, 0.8 \mathrm{MgCl}_{2}, 10 \mathrm{HEPES}, 10$ glucose, 0.005 tetrodotoxin, and 0.1 picrotoxin. The solution was adjusted to $\mathrm{pH} 7.35$ with $\mathrm{NaOH}$, which flowed at a rate of $0.5 \mathrm{ml} / \mathrm{min}$. The recording electrode contained (in mM): $140 \mathrm{KCl}, 11$ EGTA, $1 \mathrm{CaCl}_{2}, 10 \mathrm{HEPES}$, and 2 $\mathrm{Na}_{2}$-ATP, adjusted to $\mathrm{pH} 7.35$ with KOH. Outward currents were evoked by step depolarization from a holding potential of $-90 \mathrm{mV}$. For each cell, currents evoked with depolarizing steps to $40 \mathrm{mV}$ were recorded immediately before and $10 \mathrm{~min}$ after the application of the PKC activator phorbol-12,13-dibutyrate $(300 \mathrm{~mm})$ in the bath. The degree of attenuation produced by phorbol-12,13-dibutyrate $(300 \mathrm{~mm})$ was then calculated.

Transfection of Purkinje cells in organotypic cultures with the gene gun. To determine the effect of Gö6976 on Purkinje cell axonal growth (see below), the Helios Gene Gun system (Bio-Rad, Ivry-sur-Seine, France) was used to transfect organotypic culture with enhanced green fluorescent protein (EGFP). To prepare DNA-gold particles, $12 \mathrm{mg}$ of gold beads (radius, $1.0 \mu \mathrm{m}$; Bio-Rad) were washed with ethanol, and $50 \mu \mathrm{l}$ of $0.05 \mathrm{M}$ spermidine (Sigma) was added to theses particles. Then $24 \mu \mathrm{g}$ of plasmid DNA (pCMV-EGFP, which encodes EGFP; Clontech, Ozyme, Montigny le Bretonneux, France) was added to the mixture. The suspension was mixed with $50 \mu \mathrm{l}$ of $1 \mathrm{M} \mathrm{CaCl}_{2}$, vortexed, and precipitated at room temperature. The suspension was used to prepare the cartridge as described in the manual (Bio-Rad). 

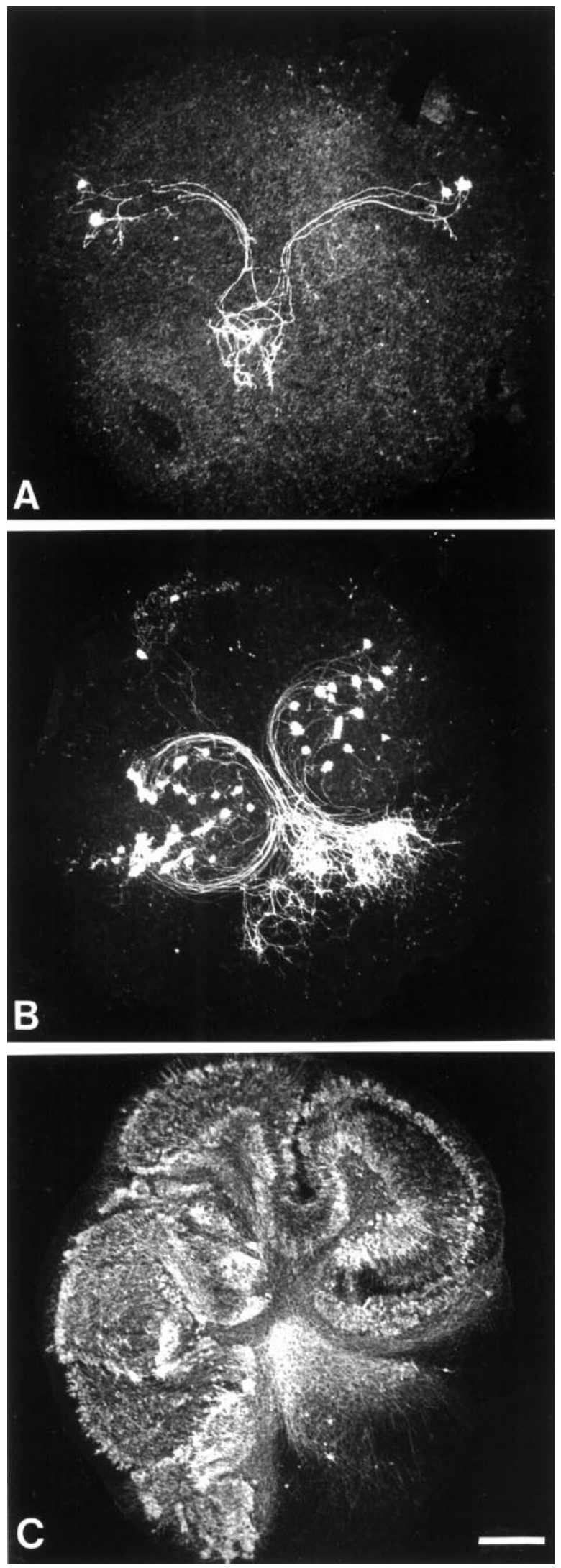

Figure 1. Definition of three separate groups of Purkinje cell survival in organotypic culture. Photomicrographs of P3 mouse cerebellar slices, nontreated (control; $A$ ) and treated with IGF-I $(B)$ or the PKC inhibitor Gö6976 $(C)$ are shown. These slices were maintained for $5 \mathrm{~d}$ in vitro and immunostained with anti-CaBP antibodies to label Purkinje cells. $A$, Very
The organotypic cultures taken from P3, P5, P7, and P10 cerebella were set up as described above with or without $2 \mu \mathrm{M}$ Gö6976. Twenty four hours later, the slice cultures were bombarded with a Helios Gene Gun at $220 \mathrm{psi}$, maintained in culture for 5 extra days before being fixed during $1 \mathrm{hr}$ in $4 \%$ paraformaldehyde in phosphate buffer $(0.1 \mathrm{M}) \mathrm{pH} 7.4$, washed in PBS, and removed from the Millicell to be processed for confocal analysis.

The axonal arbors of Purkinje cells were studied on P3, P5, P7, and P10 cultures treated or not with Gö6976 $(2 \mu \mathrm{M})$. The cultures were analyzed using a Leica TCS 4D confocal microscope to reveal the presence of double axons and the emergence point of multiple collateral.

Quantification of the regeneration in presence or absence of Gö6976. Microphotographs of each individual axotomized slice were digitally scanned with a Nikon CP-9003 camera and analyzed using Imstar (Paris, France) software. The contour of the area covered by the axonal processes in the apposed dorsal half of the slice was acquired by hand with computer-aided filling using a specially devised package from Imstar (see Fig. $5 C, D)$. This measure takes into account both regenerative axon lengths and numbers. In addition, the lengths of the three longest axons per coculture were measured on microphotographs using a curvimeter The means and SEMs were calculated. Data were statistically analyzed using the Student's $t$ test.

\section{RESULTS \\ Effects of trophic factors and protein kinase inhibitors on P3 Purkinje cell survival in organotypic cultures}

Previous studies with cerebellar organotypic cultures have shown that Purkinje cell survival is age-dependent (Dusart et al., 1997). In mouse, apoptotic Purkinje cell death, as demonstrated by terminal deoxynucleotidyl transferase-mediated biotinylated UTP nick end-labeling, DNA ladder, and electronic microscopic techniques, peaks at P3 (Ghoumari et al., 2000). In P3 cultures after 5 DIV, the number of surviving Purkinje cells was very small (Fig. 1A). Therefore, we selected P3 murine cerebellar slices kept for 5 DIV to test the ability of factors to enhance Purkinje cell survival. Survival was assessed by classifying cultures into three groups (defined in Materials and Methods and Fig. 1).

\section{BDNF, NT-3, and IGF-I have marginal effects on Purkinje cell survival}

After 5 DIV, Purkinje cell survival was practically the same in the slices treated with BDNF or NT-3 and in the control slices. In all cases, very few Purkinje cells survived; the majority of the slices belonged to group I (Fig. $1 A$ ), and none of the slices were in group III (Fig. $2 A$ ). Only the treatment with IGF-I elicited some improvement on Purkinje cell survival (50\% of slices belonged to group II; Figs. $1 B, 2 A$ ). A protective effect was noted when NT-3 and IGF-I were used in combination, in which $\sim 15 \%$ of the cultures showed the highest survival rate, belonging to group III (Fig. 2A). However, the application of trophic factors, used here, alone or in combination, was not sufficient to rescue the majority of Purkinje cells from cell death.

\section{PKC inhibitors increase Purkinje cell survival in organotypic cultures}

Several PK inhibitors, such as KT5720 (PKA inhibitor), KT5823 (PKG inhibitor), and Gö6976 (PKC inhibitor), were applied to the cultures. Only Gö6976 was efficiently protective after 5 DIV (Fig. $2 B ; 100 \%$ of the slices were in group III; Fig. $1 C$ ), whereas

few Purkinje cells are present, without groups of $>20$ Purkinje cells. This slice was included in group I. $B$, In this slice, there is at least one cluster of $>20$ Purkinje cells (group II). $C$, The slice contains a cluster of $>50$ Purkinje cells and was included in group III (see Materials and Methods). Scale bar, $250 \mu \mathrm{m}$. 


\section{A) Trophic factors}

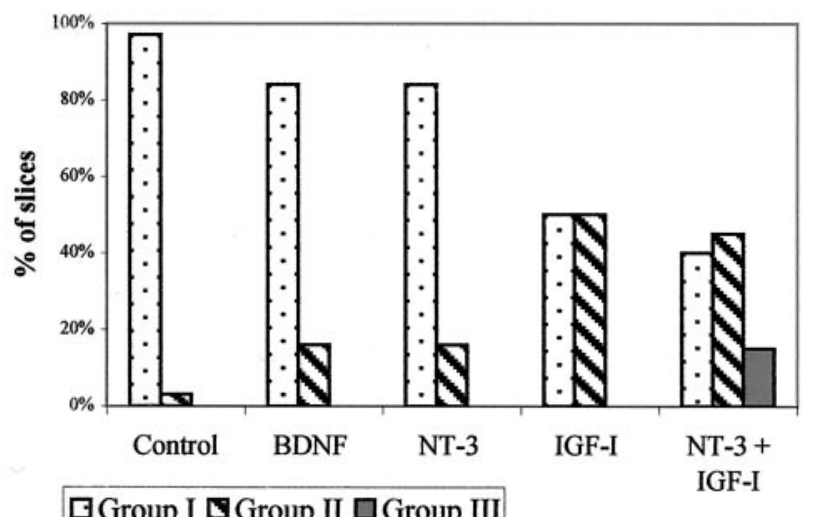

B) Protein Kinase (PK) inhibitors

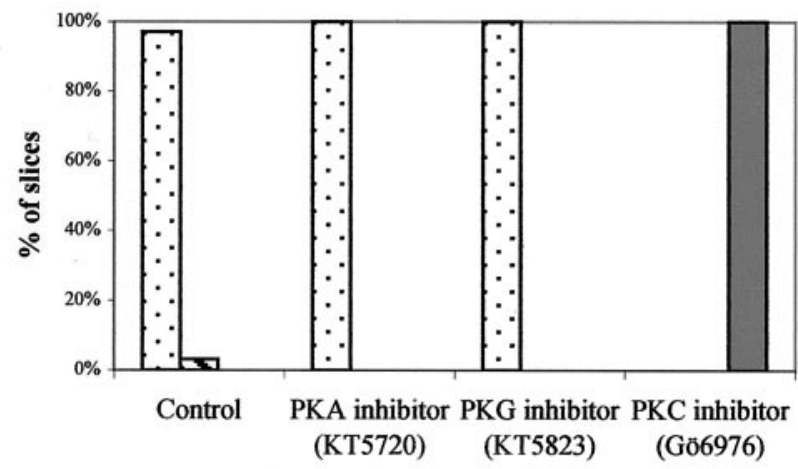

C) No excitotoxycity of BDNF

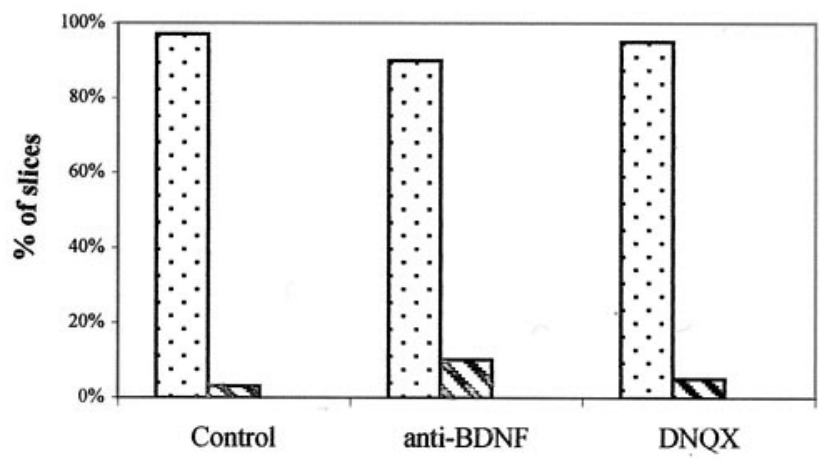

\section{D) PKCI transgene}

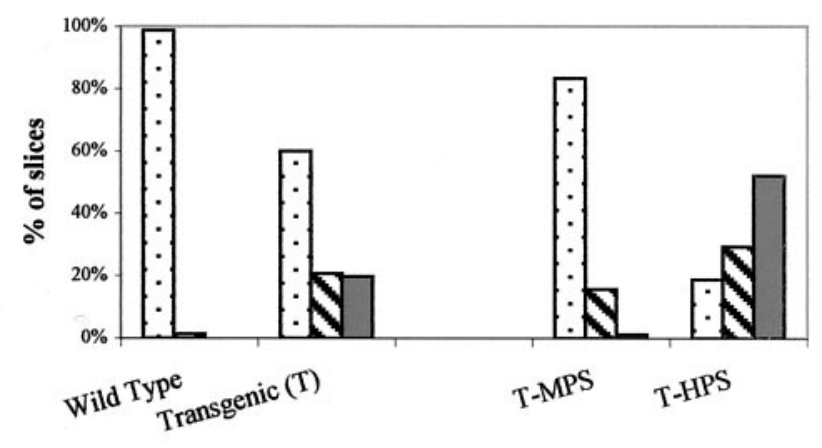

\section{E) PKCI transgene: Purkinje cell counts}

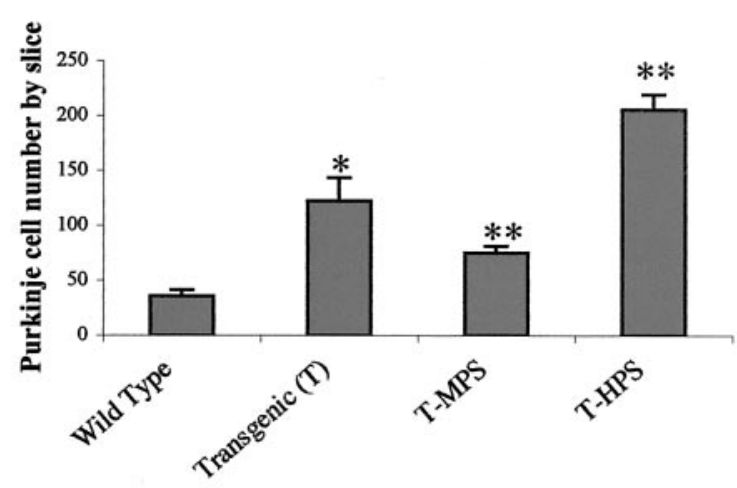

Figure 2. Quantitative analysis of Purkinje cell survival after trophic factors and protein kinase inhibitor treatment. Histograms illustrate the percentages of P3 cerebellar slices maintained at 5 DIV belonging to groups I-III (as described in Materials and Methods and in Fig. 1) after different treatments. $A$, The slice cultures were not treated (Control) or treated separately with BDNF, NT-3, IGF-I, or NT-3 plus IGF-I. The survival of Purkinje cells was always low. Indeed, most of the slices were in group I (without groups of $>20$ Purkinje cells), and few slices belonging to group III ( $15 \%$, with at least 1 cluster of $>50$ Purkinje cells) were obtained only when NT-3 was combined with IGF-I. B, Slices treated with KT5720 (PKA inhibitor), KT5823 (PKG inhibitor), or Gö6976 (PKC inhibitor). Note that only the PKC inhibitor (Gö6976, $2 \mu \mathrm{M}$ ) permitted survival of the majority of these cells; all slices belonged to group III. $C$, Slices treated with an antibody against BDNF or DNQX (the non-NMDA glutamate receptor antagonist). Note that the majority of the slices exhibited a very low survival rate of Purkinje cells, belonging to group I. D, The survival, after 5 DIV, of Purkinje cells was higher in P3 organotypic cerebellar cultures taken from L7-PKCI transgenic mice, in which the pseudosubstrate PKC inhibitor was

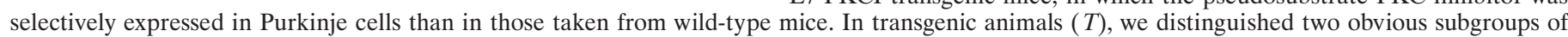

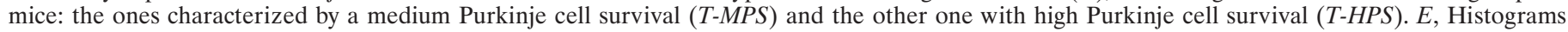

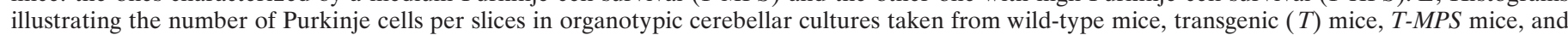

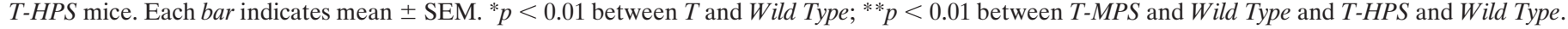

KT5720 and KT5823 had no effect (all the slices were in group I; Fig. 2B). Thus, only PKC appears to be implied in the apoptotic death.

However, Gö6976 also inhibits the Trk receptors (Behrens et al., 1998). Furthermore, work by Morrison and Mason (1998), on the survival of purified P0-P1 Purkinje cells in vitro, has shown that BDNF exerts either a protective (on isolated Purkinje cells) or a deleterious action (when Purkinje cells were cocultured with granule cells). The latter effect is thought to be mediated by glutamate release from granule cells. To determine whether this excitotoxic mechanism via BDNF and granule cells occurs in our model, we used anti-BDNF-IgG-blocking antibodies and DNQX (a non-NMDA glutamate receptor antagonist). Neither antiBDNF nor DNQX revealed protective action of Purkinje cells at 5 DIV (Fig. 2C). These results strongly suggest that the action of Gö6976 was mediated not through the blockade of Trk receptors but through its inhibitory action on PK activity.

To corroborate the above-reported results and, mainly, to show 


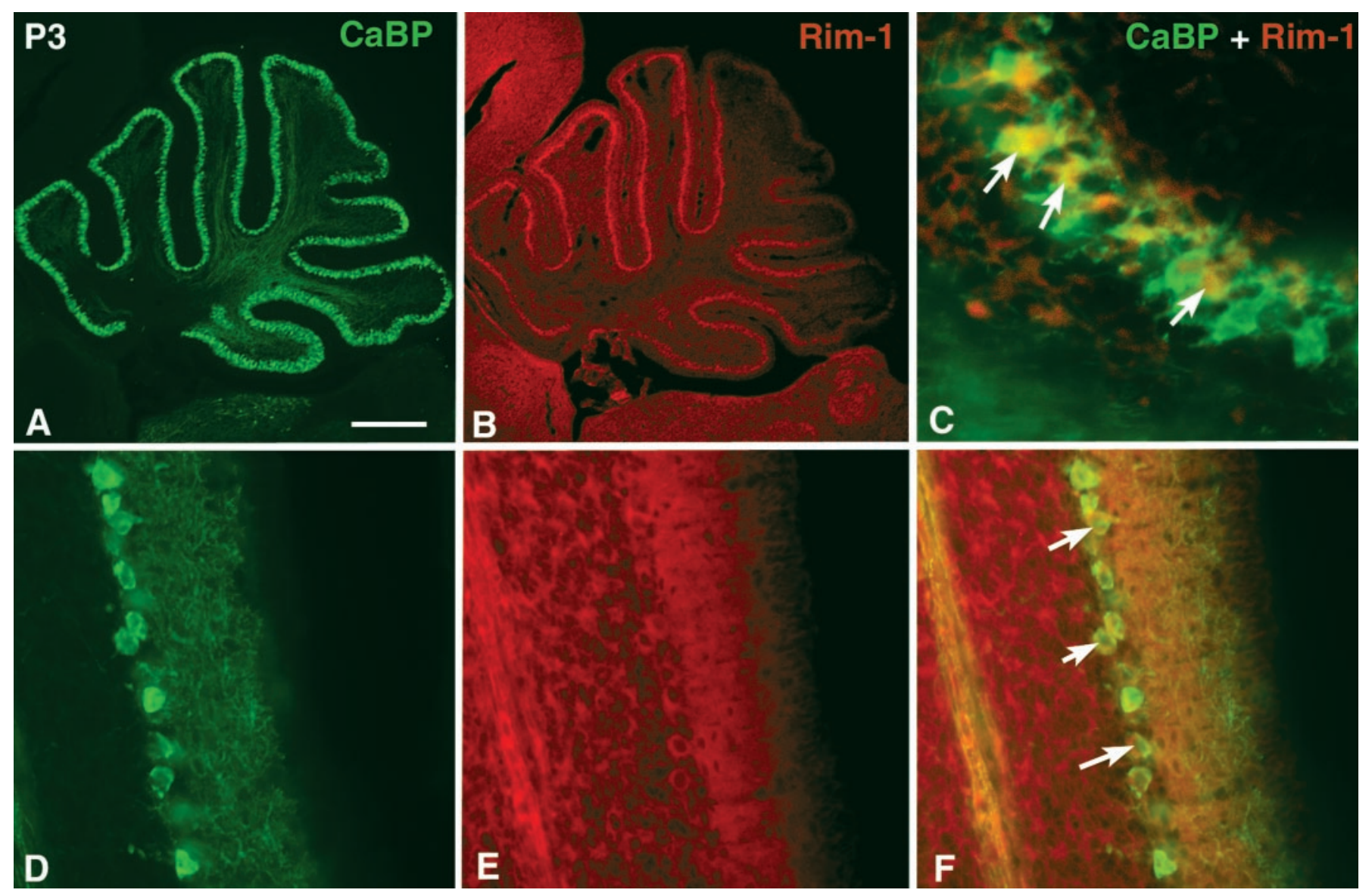

Figure 3. PKC expression in Purkinje cell layer using Rim-1 staining. Sections from a $\mathrm{P} 3$ mouse $(A-C)$ and from a P10 mouse $(D-F)$ were double-labeled using $\mathrm{CaBP}$ immunostaining $(A, D$, green $)$ and Rim-1 staining $(B, E$, red $)$. Note that in both cases, the Purkinje cell layer is double-labeled (compare $A$ with $B$ and $D$ with $E$ ). At P10 the granule cell layer is also stained with Rim-1 $(E, F)$. At P3 as well as P10, most of the Purkinje cells are double-labeled ( $C, F$, arrows). Scale bar: $A, B, 200 \mu \mathrm{m} ; C, 50 \mu \mathrm{m} ; D-F, 70 \mu \mathrm{m}$.

that the observed effect on Purkinje cell survival was the result of a direct inhibition of the Purkinje cell PKC activity, we analyzed the survival of these neurons in P3 organotypic cerebellar cultures taken from L7-PKCI transgenic mice after 5 DIV. In the two litters studied, very few surviving Purkinje cells were found in wild-type animals (5 of 17 animals; $66 \%$ of the slices were in group I; Fig. 2D). On the contrary, in the transgenic animals (identified by PCR), there was a significant although small increase in Purkinje cell survival (Fig. 2D; $21 \%$ were in group II, and $19.63 \%$ were in group III). However, in a more detailed analysis, two obvious subgroups of transgenic mice were easily recognized: one (half of the transgenic mice, 8 of 17) with a slight increase of Purkinje cell survival (named medium Purkinje cell survival, $15.54 \%$ of the slices in group II; Fig. 2D) and another one with a much more effective increase of Purkinje cell survival (named high Purkinje cell survival, 4 of 17 animals; 52\% in group III; Fig. 2D). To be sure that there are differences between wild-type and the different groups of transgenic mice, we counted the total number of Purkinje cells per slice, and we calculated the means. We found $35 \pm 6$ Purkinje cells per slice in wild-type, $122 \pm 21$ in transgenic, $75 \pm 6$ in transgenic medium Purkinje cell survival, and $205 \pm 14$ in transgenic high Purkinje cell survival groups (Fig. 2E). There are statistical differences between wildtype and transgenic $(p<0.01)$, wild-type and medium Purkinje cell survival $(p<0.001)$, and wild-type and high Purkinje cell survival $(p<0.001)$ groups. The occurrence of two clearly cut subgroups among the transgenic mice suggests that some mice (those that exhibited better Purkinje cell survival) had a higher level of PKC inhibition than others. The Mendelian distribution of the two subgroups (25\% with highest survival and $50 \%$ with lower survival) suggests that they belonged respectively to homozygous and heterozygous groups for the expression of the transgene. We have analyzed the inhibition of PKC activity in the transgenic groups. As described by De Zeeuw et al. (1998), standard biochemical assays do not apply to these specific transgenic mice. Indeed, even on carefully microdissected cerebellar cortex, the Purkinje cells contribute only to a small part of the total PKC activity. To circumvent this problem, we used an electrophysiological assay. Activation of PKC by exogenous compounds such as phorbol esters and synthetic diacylglycerols has been shown to attenuate voltage-gated potassium currents in a number of cell types, including cerebellar Purkinje cells grown in culture (Linden et al., 1992).

After the application of an exogenous PKC activator (phorbol ester, $300 \mathrm{~nm}$ phorbol-12,13-diabutyrate), the attenuation of the potassium currents was $41 \pm 3.3 \%$ for the wild-type animals $(n=$ $6), 16 \pm 3.6 \%$ for the heterozygous animals $(n=6)$, and $8 \pm 3.2 \%$ for the homozygous animals $(n=6)$ when we looked at the peak values. The attenuation produced by phorbol esters is equally strongly blocked by the PKC inhibitor chelerythrine $(10 \mu \mathrm{M} ; 7 \%$ $\pm 2.8 \%$ attenuation of peak current). Thus, in the homozygous animals, the inhibition of the PKC activity is increased twice 

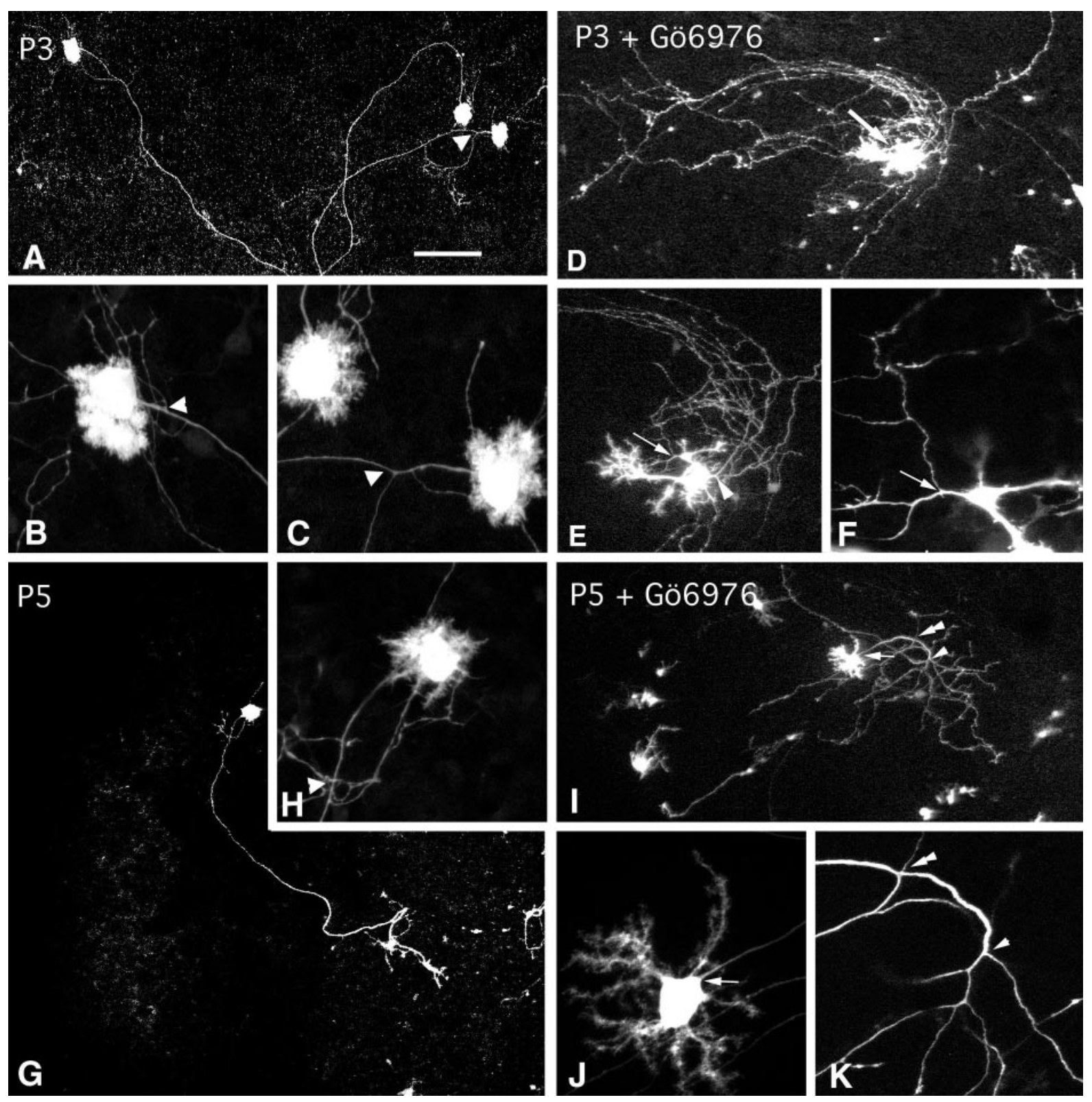

Figure 4. Confocal reconstruction of Purkinje cells in the absence and presence of Gö6976. Three-dimensional reconstructions of confocal sections were obtained using ScanWare software (Leica TCS 4D) of P3 $(A-F)$, and P5 mice $(G-K)$ in the absence $(A-C, G, H)$ or presence $(D-F, I-K)$ of Gö6976. The arrowheads in $A-C, H, I, K$ point to the primary branching points; the arrows in $D, E, J$ and the arrowhead in $E$ point to axon emerging points. PKC inhibitors exert important qualitative effects on dendritic and axonal arbors (compare $A-C$ with $D, F$ for P3; $G, H$ with $J, K$ for P5). Magnification: $A$, $D, G, I, 10 \times ; E, 20 \times ; B, C, F, H, J, K, 100 \times$.

when compared with the inhibition of the PKC activity in heterozygous animals and is comparable with that produced by a saturating concentration of an exogenous PKC inhibitor.

\section{Expression of PKC in Purkinje cells}

The presence of PKC in developing Purkinje cells was revealed by double labeling with $\mathrm{CaBP}$ immunostaining and Rim-1 staining. At P3, strong Rim-1 staining, indicative of the presence of PKC, was observed almost exclusively in the "Purkinje cell plate" and in cells with colocalized $\mathrm{CaBP}$ immunoreactivity (Fig. $3 A-C$ ). From P10, most of the CaBP-positive neurons, which were already aligned into a monolayer, also exhibited Rim-1 staining both in the soma and in the dendrites. However, the Rim-1 staining was not only confined to Purkinje cells, because it also occurred in the granular cell layer (Fig. $3 D-F$ ).

\section{Gö6976 enlarges Purkinje cell dendritic fields and increases axonal collateralization up to P7}

In CaBP-immunostained cultures, Gö6976 appears to increase not only cell survival but also neuritic outgrowth (Fig. 1C). To evaluate this presumptive action on neurites, we performed morphological analyses of dendritic and axonal arbors on isolated Purkinje cells, visualized by gene gun transfection using the pCMV-EGFP constructs. The transfected cells expressed EGFP in their somata and whole dendritic arbors, but distal axonal plexuses in the deep nuclear region could not be visualized after 


\section{A: Survival}
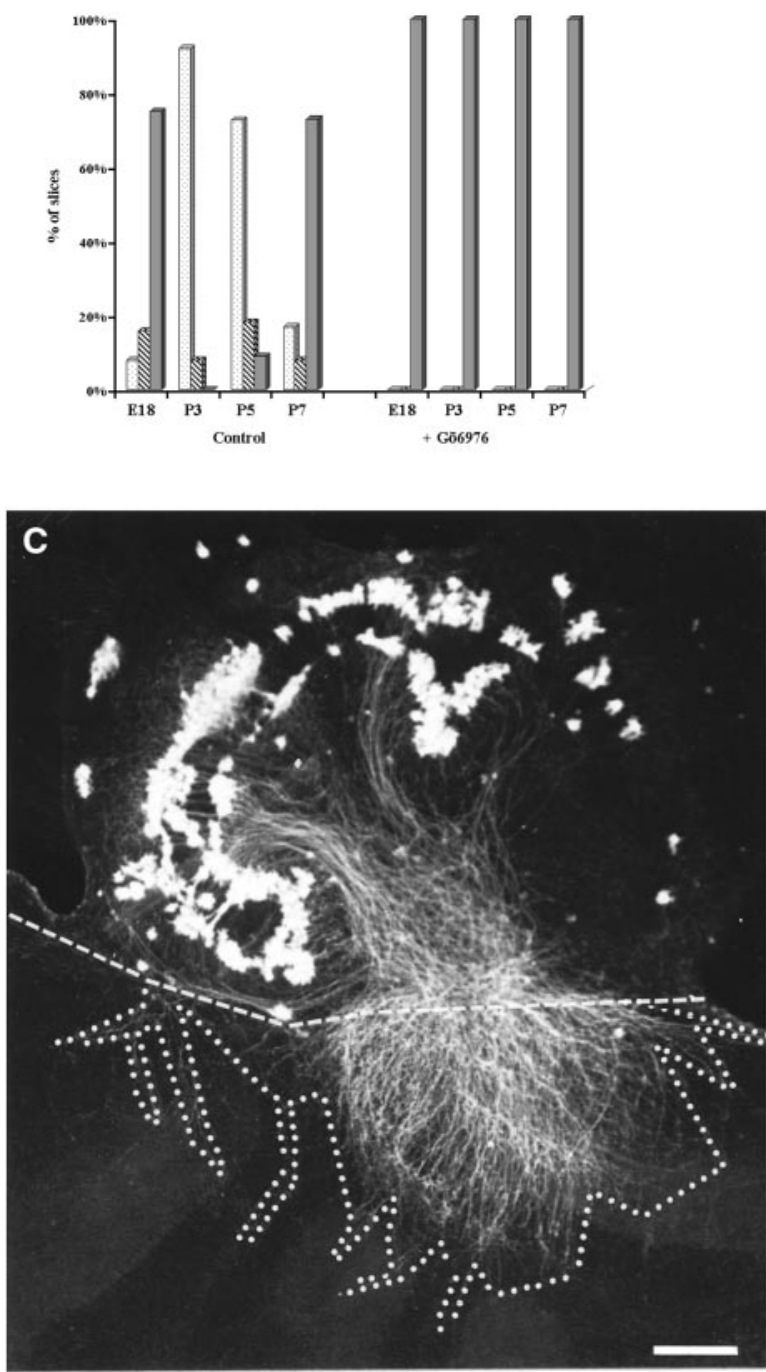

E: Surface of regenerative axons

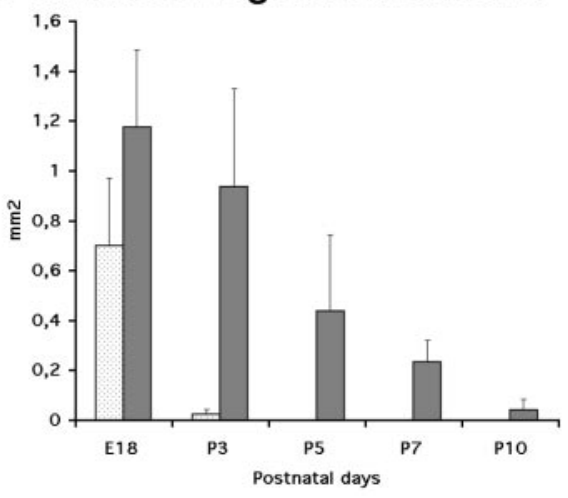

\section{B: Survival after axotomy}
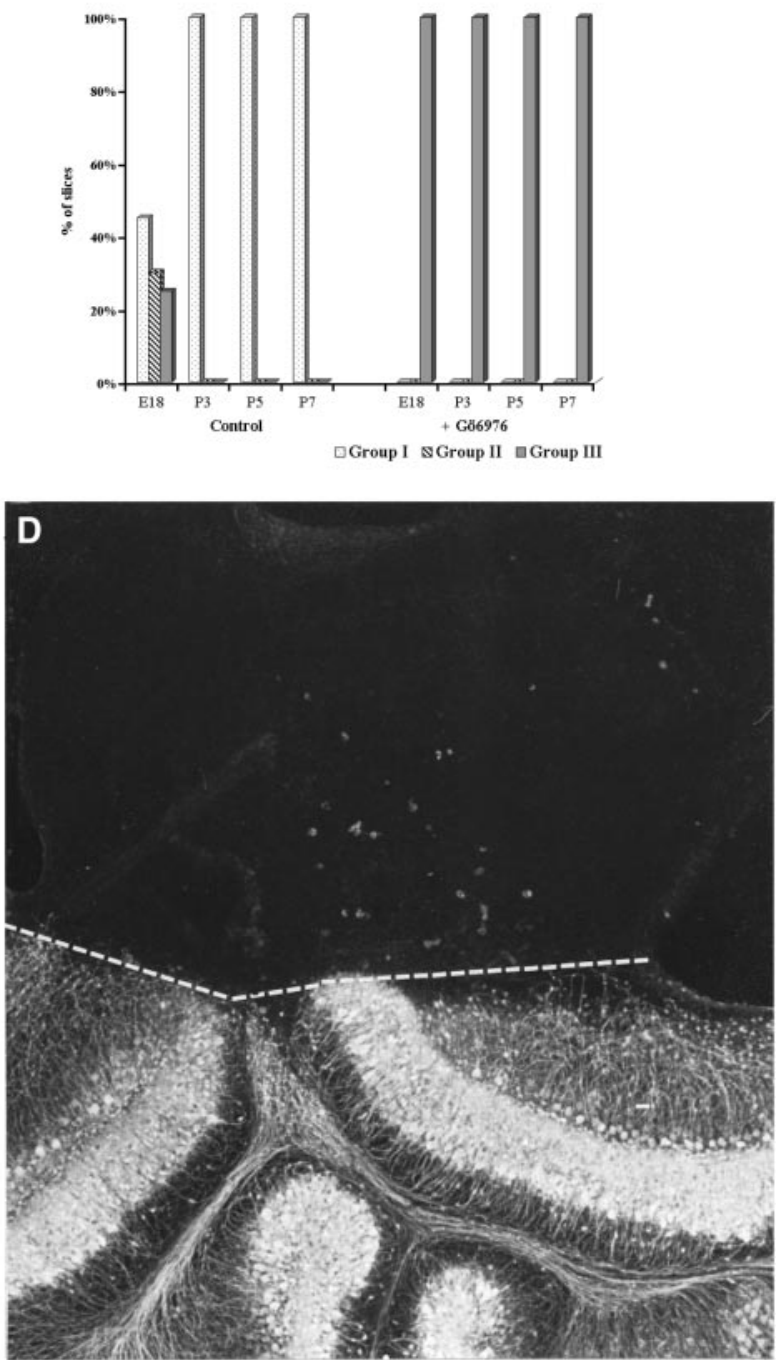

F: Length of the longest regenerative axon

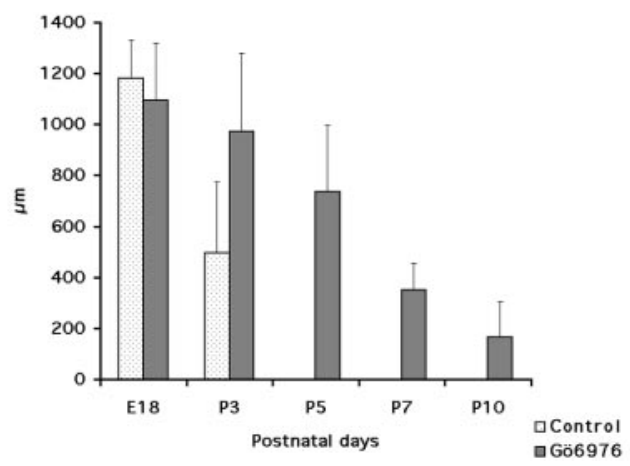

Figure 5. Purkinje cell survival and regeneration after axotomy in the presence or absence of Gö6976. $A$, $B$, Quantitative evaluation of Purkinje cell survival in organotypic cultures $(A)$ and after axotomy $(B)$. The three groups of slices $(I-I I I)$ were defined according to the number of Purkinje cells and immunostained with anti-CaBP antibodies as described in Materials and Methods and Figure 1. Interestingly, although without axotomy $(A)$ most of the E18 and P7 slices were in group III (with high Purkinje cells survival), after axotomy $(B)$ they were in group I (with low Purkinje cell survival). However, with or without axotomy, high Purkinje cell survival is always improved by the treatment of the slices with $2 \mu \mathrm{M}$ Gö6976. $C, D$, Coculture of the dorsal region of a wild-type P0 mouse cerebellar slice with the dorsal region of split P10 cerebellar slices taken from a CaBP-null mutant. The regenerative axons are CaBP-immunostained $(C)$, whereas the P10 Purkinje cells in the CaBP-null mutant are parvalbumin-immunostained $(D)$. The double labeling permits evaluation without ambiguity of the limits between the two cultures (dashed lines). The area delineated by the dotted line in $C$ represents an example of how we have drawn the surface occupied by the regenerative axons. Scale bar, $200 \mu$ m. $E$, Means of the surface covered by regenerative axons (an example of such a surface is presented in $C$ ) with or without Gö6976 at different ages. $F$, Mean of the lengths of the three longest regenerative axons per slice. 
5 DIV. Because of the low transfection efficiency (no more than 15 Purkinje cells per slice in those with high cellular survival), this method was not suitable for the analysis of Purkinje cells in untreated slices, in which Purkinje cell survival is low. Isolated Purkinje cells from CaBP-immunostained P3 or P5 control slices were therefore included in the analysis. In untreated explants of P3 cerebellum cultured for $5 \mathrm{~d}$, the few surviving Purkinje cells were in the stage of "stellate cells" (Armengol and Sotelo, 1991), with abundant somatic appendages arranged in a multipolar manner (Fig. 4B,C). The basal pole gave off one single thinner process, the axon (Fig. 4A-C). In Gö6976-treated P3 explants, the Purkinje cells exhibited much more elaborate and mature-like dendritic arbors (Fig. 4D,E). Most of the Purkinje cell somatic appendages had reabsorbed, and one to three stem dendrites emerged from the cell body (Fig. 4D,E). These stem dendrites branched into secondary and tertiary segments (Fig. 4D,E), which exhibited the most mature appearance. The enhancing action of Gö6976 on dendritic arbors was also evident in Purkinje cells from P5 treated slices after 5 DIV (Fig. 4, compare $H, J$ ) but vanished in older cerebellar slices (data not shown).

The analysis of axonal arbors was confined to the segments and collateral branches of the cortical gray matter. In control slices (P3, P5, P7, and P10), the axon emerged from the somatic basal pole and gave rise to one or two recurrent collaterals (Fig. 4A,G), as in cerebellum in vivo (Crepel et al., 1980; Armengol and Sotelo, 1991). These collaterals emerged far from the initial segment, branched at an acute angle, and ascended in the granular layer to end into a fanlike terminal array of branches. The most surprising finding concerned the axon in P3 treated slices, which after 5 DIV could be double, one emerging from the somatic basal pole and the supernumerary one from emerging from a dendritic branch (Fig. 4E,F), and much more collateralized (Fig. 4, compare $A, D$ ). Collateralization occurred close to the initial segment as multiple branches emerging from a single branch point (Fig. 4I,K). These branches did not follow an ascending direction but descended in a gradually divergent manner, like a "comet tail" shape (Fig. $4 D, I)$. The percentage of Purkinje cell axons with a point of multiple collateralization progressively decreased with age. Thus, in P3 slices treated with Gö6976, 70\% of the analyzed Purkinje cells possessed at least one point with the emergence of more than two collaterals. They were only $60 \%$ in P5 animals and $40 \%$ in P7 animals and did not occur at P10.

\section{Gö6976 enhances Purkinje cell survival after axotomy but not axonal regeneration}

We tested whether Gö6976 could improve regeneration of axotomized Purkinje cells. To this aim, we first determined whether the age-death relationship observed for intact Purkinje cells (see above) also occurred after axotomy and whether Gö6976 could also prevent axotomy-induced death. Although mature Purkinje cells in P10 slices were extremely resistant to axotomy (Dusart et al., 1997), immature Purkinje cells in E18 slices were, despite their high survival rate in intact slices, sensitive to axotomy. Thus, dorsal halves of transected E18 slices lost many Purkinje cells ( $75 \%$ of intact slices belonged to group III; Fig. $5 A$; whereas only $25 \%$ of the transected slices belonged to group III; Fig. $5 B$ ). The high incidence of Purkinje cell death in P3 and P5 intact slices (most of them already belonged to group I) prevented us from determining directly their resistance to axotomy. Most Purkinje cells died in P7 axotomized slices (all of the slices belonged to group I; Fig. 5B). Thus, from E18 to P7, Purkinje cells are very sensitive to axotomy. In contrast, the Gö6976-treated slices of the four tested ages, intact or transected, were all classified in group III (Fig. 5A,B). Thus, inhibition of PKC enhances resistance to axotomy in Purkinje cells taken from E18 to P7 cerebella.

By applying a previously developed setup (Dusart et al., 1997), in which cerebellar slices amputated of their ventral halves were apposed to ventral halves of the cerebellar slices taken from P10 transgenic mice with inactivation of the calbindin gene $(\mathrm{CaBP}-/-)$, we tested the regenerative capabilities of young Purkinje cells (Fig. 5C,D). Numerous surviving Purkinje cells in untreated cerebellar slices taken from E18 animals massively regenerated their axons after 5 DIV (Fig. 6A). Regenerating axons invaded the $\mathrm{CaBP}-/-$ cerebellar slices (Fig. 6C,D). However, when P3 or P5 explants were used, very few of the surviving Purkinje cells were able to regrow axons (Fig. 6C,F). On the contrary, the few survivors retracted their proximal axonic stumps and exhibited atrophy, disruption of their dendritic trees, or both (Fig. 6E). The situation was somewhat different when using P7 slices. Most of the few surviving Purkinje cells did not retract their axons and exhibited normal-looking dendritic trees (Fig. 6H). However, the severed axons did not regenerate (Fig. $6 H)$. Finally, Purkinje cells in P10 slices were extremely resistant to axotomy, and all of them survived without retraction of their proximal stumps but did not regenerate (data not shown).

When similar experiments were repeated on Gö6976-treated cerebellar cultures, because of the important increase in the number of surviving axotomized Purkinje cells, the areas covered with the regenerating axons were much larger than in untreated cultures (Fig. 5E). However, even with E18 slices, those with massive regeneration, the longest axon outgrowth did not significantly change with the treatment (Figs. 5F, 6A,B). Similarly, Purkinje cell regeneration was also strong in P3 treated slices, but the surface areas and maximal lengths of regenerating axons were smaller than at E18 (Figs. 5E,F, 6D). In P5 and P7 treated slices, only a few of the numerous surviving Purkinje cells were capable of axon growth (Fig. 6G,I). Thus, even in the presence of Gö6976, the Purkinje cell regenerative capability decreased gradually with age and was minimal at P7; only very few cells regenerated their axons, and their outgrowth did not go beyond $250 \mu \mathrm{m}$ (Figs. 5E,F, 6I). Finally, Gö6976 did not exert any regenerative action on P10 Purkinje cells. Thus, the regenerative capability of Purkinje cells in organotypic cultures, even when treated with Gö6976, is a progressively disappearing process, independent of the survival of these neurons (Fig. $7 A, B$ ).

\section{DISCUSSION}

Here we show that trophic factors (BDNF, NT-3, and IGF-I) are not able to rescue a large number of Purkinje cells from apoptotic death in P3 organotypic cerebellar cultures kept for $5 \mathrm{~d}$ in vitro, whereas the inhibition of PKC activity (either by Gö6976 or by using a transgenic mouse line in which a pseudosubstrate PKC inhibitor has been specifically targeted to Purkinje cells) is enough to block the cell death process. In addition, Gö6976 treatment also accelerates Purkinje cell dendritic differentiation and induced axon collateralization up to P7. Conversely, after axotomy, Purkinje cell regeneration even in the presence of Gö6976 decreases rapidly between E18 and P7. Thus, the time differences encountered between Purkinje cell survival and its regenerative capability strongly suggest that $\mathrm{PKC}$ is not a mutual player in the two cell decisions: cell death and axon regeneration. 

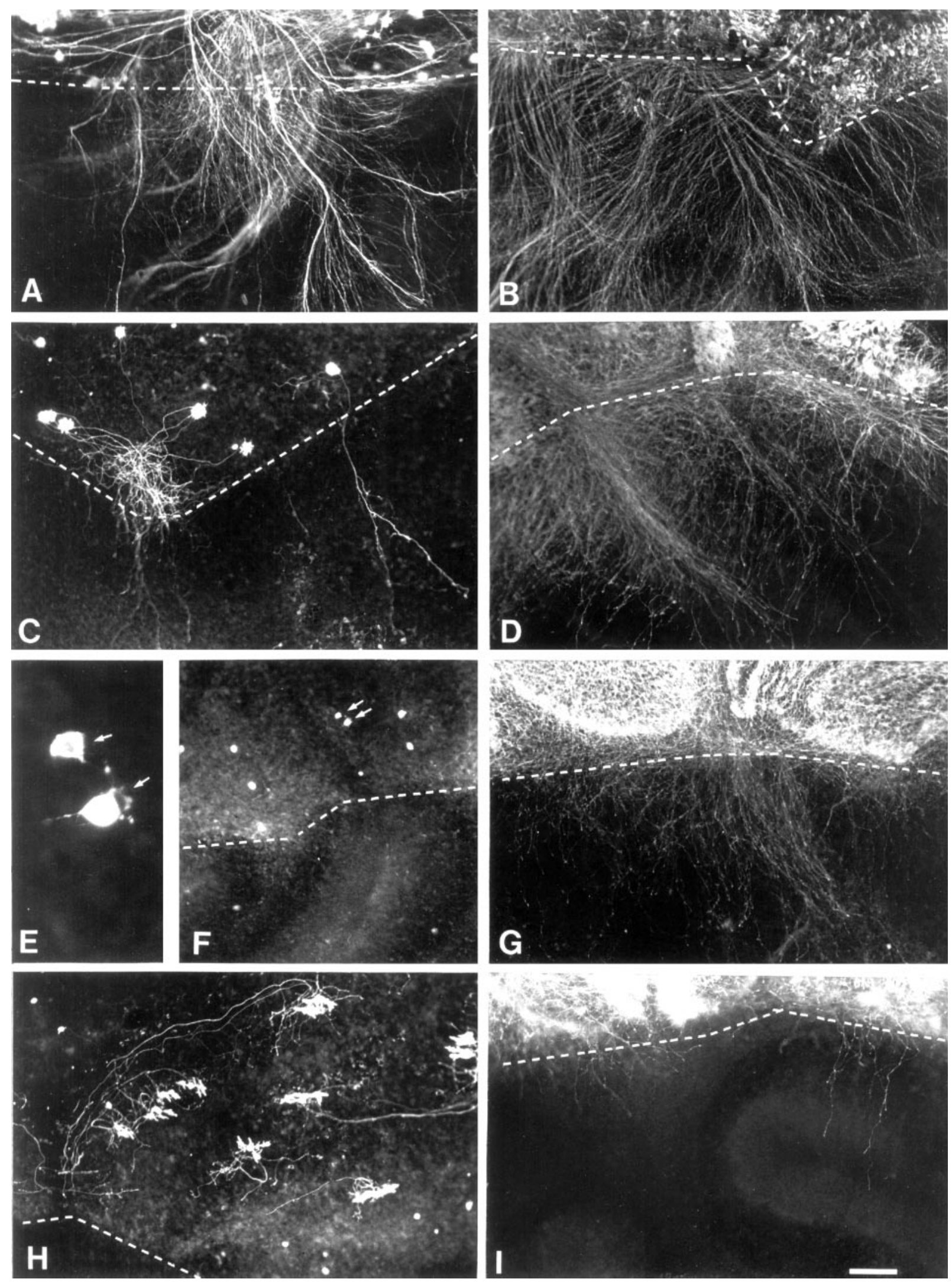

Figure 6. Axonal regeneration of Purkinje cells in the presence or absence of Gö6976. Coculture of the dorsal regions of wild-type E18 ( $A$, $B)$, P3 $(C$, $D), \mathrm{P} 5(E-G)$, and P7 $(H, I)$ mouse cerebellar slices with the dorsal region of split P10 cerebellar slices taken from a CaBP-null mutant in the absence $(A, C, E, F, H)$ or presence $(B, D, G, I)$ of Gö6976 is shown. The dashed lines represent the borderlines between the two cocultures. Note that the number of regenerative axons decreases with age in the absence (compare $A, C, F, H)$ or presence $(B, D, G, I)$ of Gö6976. For each time point, the regenerative capability is always stronger in the presence of Gö6976 than in its absence (compare $A$ with $B, C$ with $D, F$ with $G, H$ with $I$ ). $E$, Enlargement of $F$ (arrows point to the same cell in $E, F)$. Scale bar: $A-D, F-I, 150 \mu \mathrm{m} ; E, 22.5 \mu \mathrm{m}$. 


\section{A Effects of Gö6976 on survival and axonal regeneration}

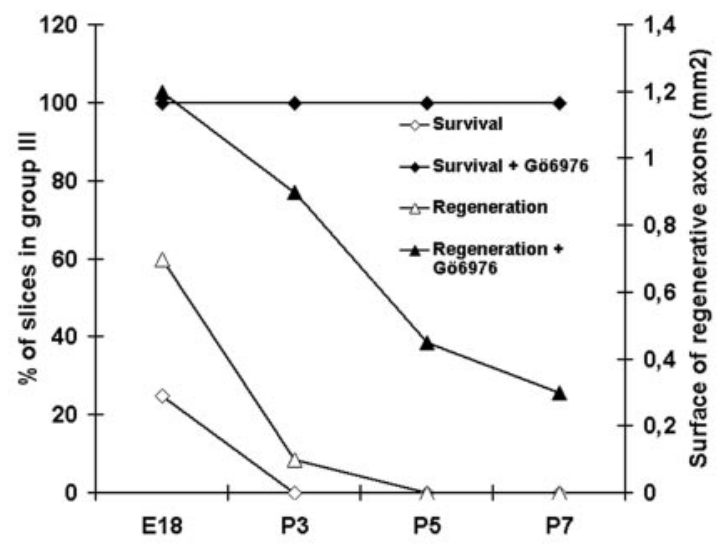

B
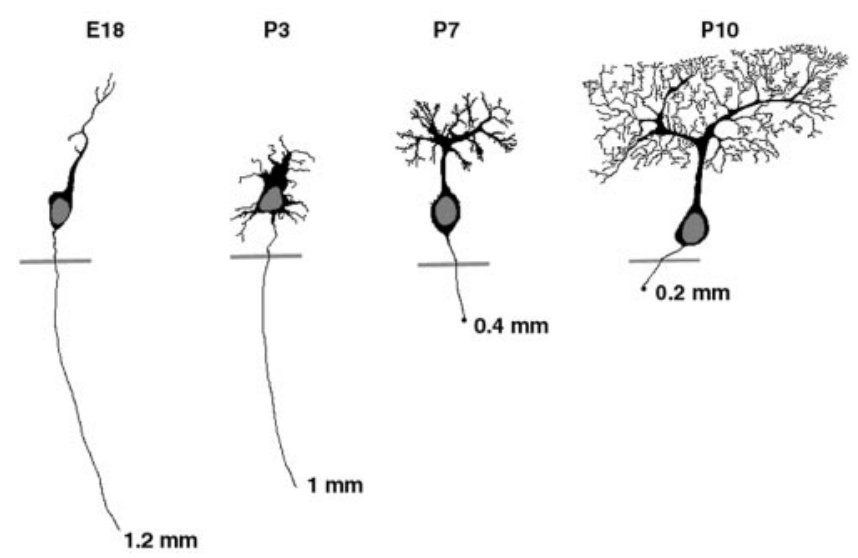

Figure 7. Purkinje cell regeneration. A, Comparison of Purkinje cell survival and regeneration in the presence or absence of Gö6976. To compare the effect of Gö6976 on Purkinje cell survival and regeneration after axotomy, we have combined results from Figure $4 B, E$ on a same double-axis graph. The left $y$-axis represents the survival curves, indicating the percentage of slices in group III (see Materials and Methods and Fig. 1). The right $y$-axis represents the regeneration curves, indicating the surface of regenerative axons (square millimeters). Note that although the effect of Gö6976 on Purkinje cell survival is important whatever the ages of mice from which the slices were taken, the effect of Gö6976 on axonal regeneration decreases with age. The two curves concerning axonal regeneration are almost parallel. $B$, Schematic representation of the regenerative capabilities of Purkinje cells during development (adapted from Chedotal and Sotelo, 1993).

\section{Neurotrophins do not significantly promote Purkinje cell survival}

During maturation, Purkinje cells express TrkB, TrkC, and IGF-I receptors (Yan and Johnson, 1988; Cohen-Cory et al., 1989; Bartlett et al., 1991; Lindholm et al., 1993; Torres-Aleman et al., 1994; Minichiello and Klein, 1996). Thus, their respective ligands (BDNF, NT-3, and IGF-I) are presumably involved in the survival of these neurons. This possibility has been tested using primary cerebellar cultures (Mount et al., 1994; Larkfors et al., 1996; Lindholm et al., 1997), cultures of purified Purkinje cells, or cocultures of Purkinje and granule cells (Baptista et al., 1994; Morrison and Mason, 1998). The most remarkable result, despite the partial effect obtained with the growth factors, is that Purkinje cell survival depends on the cellular populations present in the cultures, emphasizing the importance of cell-cell interactions in this neuronal survival (Morrison and Mason, 1998). Using our organotypic cultures, an optimal model for the study of Purkinje cell apoptosis in vitro (Ghoumari et al., 2000), in which all cerebellar elements occur, with the exception of extracerebellar afferent fibers, we have shown that only IGF-I, but not BDNF or NT-3, has a mild effect on Purkinje cell survival. The results strongly suggest that preventing apoptosis requires more than one trophic factor, as extensively demonstrated for motoneurons (Henderson, 1996). In favor of this assertion is the more significant improvement in Purkinje cell survival obtained here by combining NT-3 and IGF-I.

\section{PKC activity and Purkinje cell death}

Surprisingly, from the tested PK inhibitors, only Gö6976, a PKC inhibitor, was able to massively prevent Purkinje cell death. Gö6976 also inhibits Trk receptors (Behrens et al., 1998), but it is unlikely that these receptors, known to mediate neuronal survival (Kaplan and Miller, 2000), could be involved in Purkinje cell apoptosis in our cultures (see the experiments reported here using anti-BDNF antibodies and DNQX, a non-NMDA glutamate receptor antagonist). In contrast, most of our data emphasize that PKC is involved in Purkinje cell death; PKC isoforms are expressed in developing Purkinje cells, as shown previously by immunostaining (Metzger and Kapfhammer, 2000) and here by double labeling with Rim-1 (a fluorescent probe for PKC; Chen and Poenie, 1993) and calbindin immunostaining. More importantly, our in vitro experiments with the L7-PKCI transgenic mice, in which the pseudosubstrate PKC inhibitor PKC[19-31] was targeted to Purkinje cells with the L7 promotor (De Zeeuw et al., 1998), demonstrate that prevention of Purkinje cell death results from direct inhibition of Purkinje cell PKC activity. However, the Purkinje cell survival was weaker in L7-PKCI animals than the one observed after Gö6976 treatment, probably because of lower inhibition of the PKC activities. Furthermore, the difference between the two groups in the transgenic animals could be explained by the difference in PKC inhibition activity between the homozygous and the heterozygous animals. Indeed, the PKC activity is two times more inhibited in homozygous animals than in heterozygous transgenic animals.

Activation of PKC may be either proapoptotic or antiapoptotic depending on the cell type (for review, see Dempsey et al., 2000). In central neurons and neuronal cell lines, in the majority of the cases, PKC activation exerts a protective action and supports cell survival (Davis and Maher, 1994; Zirpel et al., 1998), whereas, in some instances, as in Purkinje cells, on the contrary, the inhibition of PKC activity prevents cell death (Favaron et al., 1990; Felipo et al., 1993). These opposite actions could be dependent on differential expression of PKC isoforms; at least 12 different isoenzymes are known, each one with possible different biological properties (Musashi et al., 2000). Thus, the inducing or preventing effect of PKC must depend on the regulatory pathways and on the type of involved cells. Our results emphasize the importance of PKC inhibitors in Purkinje cell survival; however, they do not reveal which ones, among the variety of regulatory pathways that are both upstream and downstream of PKC activation, are implied in this neuroprotective effect of PKC inhibition. For example, PKC- $\delta$ is emerging as a common intermediate in the apo- 
ptotic pathway induced by chemicals and irradiation. Proteolytic activation of PKC- $\delta$ by caspases releases a catalytic active fragment in cells induced to undergo apoptosis. This cleavage may serve to amplify downstream-specific events in the apoptotic pathway (Dempsey et al., 2000).

Because of the great complexity of PKC regulatory pathways and their presumptive incidence on the apoptotic process, it is obvious that much more work is still required to understand the effect of PKC on Purkinje cell death. However, one of the multiple molecular cascades influenced by PKC involves the phosphorylation of GAP-43 (Benowitz and Routtenberg, 1997). Recently, Gagliardini et al. (2000) have shown that Purkinje cell survival in explants taken from cerebella of 2-d-old GAP-43 heterozygous null mutated mice is better than in wild-type cerebellar explants. Furthermore, in a transgenic mouse line with neuronal overexpression of GAP-43, most Purkinje cells die in P10 explants, contrary to wild-type mice (Wehrlé et al., 2001). It is, therefore, possible that the deleterious action of GAP-43 expression in Purkinje cells transits through PKC. In fact, the treatment with Gö6976 of explants taken from P10 GAP-43overexpressing transgenic cerebella prevents this cell death $(\mathrm{R}$. Wehrlé and I. Dusart, unpublished results). Thus, PKC and GAP-43 are likely to be involved in the same common pathway that induces Purkinje cell death.

\section{Effect of Gö6976 on neuritic growth and axon regeneration}

The Golgi-like appearance of Purkinje cells after the gene gun EGFP transfection technology (Arnold et al., 1994; Lo et al., 1994; Wellmann et al., 1999) allowed us to determine the effects of PKC inhibition on the development of dendrites and axons. Gö6976 accelerates the dendritic differentiation (Metzger and Kapfhammer, 2000). This effect could be indirect, because the survival of Purkinje cells increases the generation of granule cells (Wechsler-Reya and Scott, 1999) and, therefore, of presynaptic inputs known to support dendritic growth and differentiation (Sotelo, 1978). In contrast, the abnormal features encountered in axonal trees of Gö6976-treated Purkinje cells, mainly the increase in abnormal collaterals (comet tail types) and the lack of subganglionic plexuses, provide evidence against accelerated differentiation. Thus, as concluded above for cell death pathways, axon collaterization is also under PKC control, at least until P7.

However, the stimulating action of PKC inhibition on Purkinje cell neuritic differentiation and growth did not change the regenerative capabilities of these neurons. Indeed, by using our coculture system (cerebellar wild-type explants apposed to cerebellar CaBP-/- explants; Dusart et al., 1997), in which quantification of regenerating axons is possible, we observed that the proportion of Purkinje cells with regenerating axons in P3, P5, and P7 Gö6976-treated slices remained constantly low. In addition, the proportion of regenerating axons rapidly declined from P3 onward, and by P7 it was practically absent. Thus, the observed increase in the surface area occupied by regenerating axons is probably just the result of the remarkable survival action of Gö6976 on both untouched and axotomized Purkinje cells (Fig. $7 A$ ). These results support the conclusion that the inhibition of PKC does not promote axonal regeneration in our system. Another interesting result emerges from the comparison of the effects of PKC inhibition on untouched and axotomized Purkinje cells. Although Gö6976 increases collateralization on some P7 Purkinje cell axons, it does not promote regeneration, providing new additional evidence in favor of a mechanistic difference between the processes of collateral sprouting and axonal regeneration.

In conclusion, our study demonstrates that, after axotomy, the two cell decisions, death and regeneration, are differentially downregulated and, therefore, are not part of the same signaling pathway. Axonal regeneration of Purkinje cells is progressively downregulated between P3 and P7, whereas cell death is downregulated only after $\mathrm{P} 7$.

\section{REFERENCES}

Airaksinen MS, Eilers J, Garaschuk O, Thoenen H, Konnerth A, Meyer M (1997) Ataxia and altered dendritic calcium signaling in mice carrying a targeted null mutation of the calbindin D28k gene. Proc Natl Acad Sci USA 94:1488-1493.

Armengol JA, Sotelo C (1991) Early dendritic development of Purkinje cells in the rat cerebellum. A light and electron microscopic study using axonal tracing in "in vitro" slices. Brain Res Dev Brain Res 64:95-114.

Arnold D, Feng L, Kim J, Heintz N (1994) A strategy for the analysis of gene expression during neural development. Proc Natl Acad Sci USA 91:9970-9974.

Baptista CA, Hatten ME, Blazeski R, Mason CA (1994) Cell-cell interactions influence survival and differentiation of purified Purkinje cells in vitro. Neuron 2:243-260.

Bartlett WP, Li XS, Williams M, Benkovic S (1991) Localization of insulin-like growth factor-1 mRNA in murine central nervous system during postnatal development. Dev Biol 147:239-250.

Behrens MM, Strasser U, Choi DW (1998) Gö6976 is a potent inhibitor of neurotrophin-receptor intrinsic tyrosine kinase. J Neurochem 72:919-924

Benowitz LI, Routtenberg A (1997) GAP-43: an intrinsic determinant of neuronal development and plasticity. Trends Neurosci 20:84-91.

Campenot RB (1994) NGF and the local control of nerve terminal growth. J Neurobiol 25:599-611.

Celio MR (1990) Calbindin D-28k and parvalbumin in the rat nervous system. Neuroscience 35:375-475.

Chedotal A, Sotelo C (1993) The "creeper stage" in cerebellar climbing fiber synaptogenesis precedes the "pericellular nest"-ultrastructural evidence with parvalbumin immunocytochemistry. Dev Brain Res $76: 207-220$

Chen CS, Poenie M (1993) New fluorescent probes for protein kinase C. Synthesis, characterization, and application. J Biol Chem 268:15812-15822

Cohen-Cory S, Dreyfus CF, Black IB (1989) Expression of high- and low-affinity nerve growth factor receptors by Purkinje cells in the developing rat cerebellum. Exp Neurol 105:104-109.

Crepel F, Delhaye-Bouchaud N, Dupont JL, Sotelo C (1980) Dendritic and axonic fields of Purkinje cells in developing and $\mathrm{x}$-irradiated rat cerebellum. A comparative study using intracellular staining with horseradish peroxidase. Neuroscience 5:333-347.

Davis JB, Maher P (1994) Protein kinase C activation inhibits glutamate-induced cytotoxicity in a neuronal cell line. Brain Res 652:169-173.

Dempsey EC, Newton AC, Mochly-Rosen D, Fields AP, Reyland ME, Insel PA, Messing RO (2000) Protein kinase C isozymes and the regulation of diverse cell responses. Am J Physiol 279:L429-L438.

De Zeeuw CI, Hansel C, Bian F, Koekkoek SK, van Alphen AM, Linden DJ, Oberdick J (1998) Expression of a protein kinase C inhibitor in Purkinje cells blocks cerebellar LTD and adaptation of the vestibuloocular reflex. Neuron 20:495-508.

Dusart I, Airaksinen MS, Sotelo C (1997) Purkinje cell survival and axonal regeneration are age dependent: an in vitro study. J Neurosci $17: 3710-3726$.

Favaron M, Manev H, Siman R, Bertolino M, Szekely AM, DeErausquin G, Guidotti A, Costa E (1990) Down-regulation of protein kinase C protects cerebellar granule neurons in primary culture from glutamateinduced neuronal death. Proc Natl Acad Sci USA 87:1983-1987.

Felipo V, Minana MD, Grisolia S (1993) Inhibitors of protein kinase C prevent the toxicity of glutamate in primary neuronal cultures. Brain Res 604:192-196.

Gagliardini V, Dusart I, Fankhauser C (2000) Absence of GAP-43 can protect neurons from death. Mol Cell Neurosci 16:27-33.

Ghoumari AM, Wehrlé R, Bernard O, Sotelo C, Dusart I (2000) Implication of Bcl-2 and caspase- 3 in the age-related Purkinje cell death in murine organotypic culture: an in vitro model to study apoptosis. Eur J Neurosci 12:2935-2949.

Gianola S, Rossi F (2001) Evolution of the Purkinje cell response to injury and regenerative potential during postnatal development of the rat cerebellum. J Comp Neurol 430:101-117.

Goldberg JL, Barres BA (2000) The relationship between neuronal survival and regeneration. Annu Rev Neurosci 23:579-612. 
Henderson CE (1996) Role of neurotrophic factors in neuronal development. Curr Opin Neurobiol 6:64-70.

Herdegen T, Skene P, Bahr M (1997) The c-Jun transcription factor: bipotential mediator of neuronal death, survival and regeneration. Trends Neurosci 20:227-231.

Kaplan DR, Miller FD (2000) Neurotrophin signal transduction in the nervous system. Curr Opin Neurobiol 10:381-391.

Larkfors L, Lindsay RM, Alderson RF (1996) Characterization of the responses of Purkinje cells to neurotrophin treatment. J Neurochem 66:1362-1373.

Levi-Montalcini R (1987) The nerve growth factor 35 years later. Science 237:1154-1162.

Linden DL, Smeyne M, Sun SC, Connor JA (1992) An electrophysiological correlate of protein kinase C isozyme distribution in cultured cerebellar neurons. J Neurosci 12:3601-3608.

Lindholm D, Dechant G, Heisenberg CP, Thoenen H (1993) Brainderived neurotrophic factor is a survival factor for cultured rat cerebellar granule neurons and protects them against glutamate-induced neurotoxicity. Eur J Neurosci 5:1455-1464.

Lindholm D, Hamner S, Zirrgiebel U (1997) Neurotrophins and cerebellar development. Perspect Dev Neurobiol 5:83-94.

Lo DC, McAllister AK, Katz LC (1994) Neuronal transfection in brain slices using particle-mediated gene transfer. Neuron 13:1263-1268.

Marty S, Carroll P, Cellerino A, Castren E, Staiger V, Thoenen H, Lindholm D (1996) Brain-derived neurotrophic factor promotes the differentiation of various hippocampal nonpyramidal neurons, including Cajal-Retzius cells, in organotypic slice cultures. J Neurosci 16:675-687.

Metzger F, Kapfhammer JP (2000) Protein kinase C activity modulates dendritic differentiation of rat Purkinje cells in cerebellar slice cultures. Eur J Neurosci 12:1993-2005.

Meyer-Franke A, Kaplan MR, Pfrieger FW, Barres BA (1995) Characterization of the signaling interactions that promote the survival and growth of developing retinal ganglion cells in culture. Neuron 15:805-819.

Minichiello L, Klein R (1996) TrkB and TrkC neurotrophin receptors cooperate in promoting survival of hippocampal and cerebellar granule neurons. Genes Dev 10:2849-2858.
Morrison ME, Mason CA (1998) Granule neuron regulation of Purkinje cell development: striking a balance between neurotrophin and glutamate signaling. J Neurosci 18:3563-3573.

Mount HT, Dreyfus CF, Black IB (1994) Muscarinic stimulation promotes cultured Purkinje cell survival: a role for acetylcholine in cerebellar development? J Neurochem 63:2065-2073.

Musashi M, Ota S, Shiroshita N (2000) The role of protein kinase C isoforms in cell proliferation and apoptosis. Int J Hematol 72:12-19.

Nishizuka Y (1992) Intracellular signaling by hydrolysis of phospholipids and activation of protein kinase C. Science 258:607-614.

Schilling K, Dickinson M, Connor JA, Morgan JI (1991) Electrical activity in cerebellar cultures determines Purkinje cell dendritic growth pattern. Neuron 7:891-902.

Seil FJ, Drake-Baumann R (2000) TrkB receptor ligands promote activity-dependent inhibitory synaptogenesis. J Neurosci 20:5367-5373.

Sotelo C (1978) Purkinje cell ontogeny: formation and maintenance of spines. Prog Brain Res 48:149-170.

Stoppini L, Buchs PA, Muller D (1991) A simple method for organotypic cultures of nervous tissue. J Neurosci Methods 37:173-182.

Torres-Aleman I, Pons S, Arevalo MA (1994) The insulin-like growth factor I system in the rat cerebellum: developmental regulation and role in neuronal survival and differentiation. J Neurosci Res 39:117-126.

Wechsler-Reya RJ, Scott MP (1999) Control of neuronal precursor proliferation in the cerebellum by Sonic Hedgehog. Neuron 22:103-114

Wehrlé R, Caroni P, Sotelo C, Dusart I (2001) Role of GAP-43 in mediating the responsiveness of cerebellar and precerebellar neurons to axotomy. Eur J Neurosci 13:857-870.

Wellmann H, Kaltschmidt B, Kaltschmidt C (1999) Optimized protocol for biolistic transfection of brain slices and dissociated cultured neurons with a hand-held gene gun. J Neurosci Methods 92:55-64.

Yan Q, Johnson Jr EM (1988) An immunohistochemical study of the nerve growth factor receptor in developing rats. J Neurosci 8:3481-3498.

Zirpel L, Lippe WR, Rubel EW (1998) Activity-dependent regulation of $\left[\mathrm{Ca}^{2+}\right]_{\mathrm{i}}$ in avian cochlear nucleus neurons: roles of protein kinases $\mathrm{A}$ and $\mathrm{C}$ and relation to cell death. J Neurophysiol 79:2288-2302. 